\title{
Aa. Vv., La trilogie des dragons
}

\section{Veronica Cappellari}

\section{(2) OpenEdition}

\section{Journals}

\section{Edizione digitale}

URL: https://journals.openedition.org/studifrancesi/46414

DOI: 10.4000/studifrancesi.46414

ISSN: 2421-5856

\section{Editore}

Rosenberg \& Sellier

\section{Edizione cartacea}

Data di pubblicazione: 1 octobre 2007

Paginazione: 488-489

ISSN: 0039-2944

\section{Notizia bibliografica digitale}

Veronica Cappellari, «Aa. Vv., La trilogie des dragons», Studi Francesi [Online], 152 (LI | II) | 2007, online dal 30 novembre 2015, consultato il 24 novembre 2021. URL: http://journals.openedition.org/ studifrancesi/46414 ; DOI: https://doi.org/10.4000/studifrancesi.46414

Questo documento è stato generato automaticamente il 24 novembre 2021.

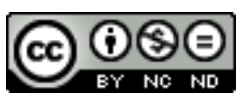

Studi Francesi è distribuita con Licenza Creative Commons Attribuzione - Non commerciale - Non opere derivate 4.0 Internazionale. 


\title{
Aa. Vv., La trilogie des dragons
}

\author{
Veronica Cappellari
}

\section{NOTIZIA}

AA. VV., La trilogie des dragons, Québec, L'instant même, 2005, pp. 171.

1 «Je ne suis jamais allée en Chine» (pp. 15 e 168) è la frase-chiave di apertura e di chiusura de La Trilogie des dragons, un'opera teatrale collettiva redatta da Marie Brassard, Jean Casault, Lorraine Côté, Marie Gignac, Robert Lepage e Marie Michaud, portata per la prima volta sulla scena il 6 giugno 1987 all'Hangar 9 del Vieux-Port di Montréal in occasione della seconda edizione del Festival de Théâtre des Amériques (FTA), per la regia di Robert Lepage, e, successivamente, presentata in una trentina di città in Nord America, in Europa e in Oceania.

Da Québec a Vancouver, passando per Toronto, La Trilogie des dragons riproduce, in una scansione ternaria, un affresco di tre differenti periodi storici della società canadese, ciascuno dei quali compone una delle tre parti in cui è suddivisa la pièce: Le Dragon vert (1932-1935), simbolo della giovinezza e dell'innocenza; Le Dragon rouge (1935-1955), emblema della terra, del fuoco e della prosperità; e, infine, Le Dragon blanc (1985), raffigurazione della rinascita. L'intera vicenda ha origine da un viaggio immaginario e favoloso compiuto da due cugine dodicenni di origine quebecchese, Jeanne e Françoise, residenti nel quartiere di Chinatown nella Québec degli anni Trenta, le quali, annoiate dalla routine quotidiana, iniziano a sognare un Oriente mitico, chimerico e ricco di colori: «Je ne suis jamais allée en Chine. Quand j'étais petite, il y avait des maisons ici. C'était le quartier chinois. Si tu grattes le sol avec tes ongles tu vas trouver de l'eau et de l'huile à moteur. Si tu creuses encore tu vas sûrement trouver des morceaux de porcelaine et de jade et les fondations des maisons des Chinois et si tu creuses encore plus loin tu vas te retrouver en Chine» (pp. 16 e 17). Di fronte alle due giovani si apre allora l'immensità del Levante. Attraverso l'immaginazione delle fanciulle, il lettore ripercorre non solo i grandi eventi storici del xx secolo (la seconda Guerra Mondiale e 
la tragica esplosione della bomba di Hiroshima), ma anche il terrore per la malattia del secolo: il cancro.

$3 \quad$ La Trilogie des Dragons, portando sulla scena numerosi personaggi di origini diverse (dei canadesi francofoni e anglofoni, un cittadino britannico, dei cinesi e dei giapponesi) che si incontrano e interagiscono, offre una singolare immagine della storia dell'immigrazione cinese in Canada. Considerata ormai una delle opere più ragguardevoli del teatro quebecchese francofono, la trilogia è il risultato di un lavoro intenso e appassionato che, come sottolinea Michel Tremblay nella prefazione all'opera, ha finalmente consentito al Québécois de souche di incamminarsi in un lungo, chimerico e mitico «voyage initiatique» fino all'Asia, paese che raffigura il «Grand Ailleurs» in cui «[ils avaient] désormais le droit d'aller vivre des choses importantes loin du centre névralgique des rancœurs» (p. 7). 